\title{
THE SURGERY OF THE ADRENAL GLANDS
}

\author{
By L. R. Broster, O.B.E., D.M., M.CH., F.R.C.S., F.A.S.A.
}

The adrenal glands are essential to life. Surgical treatment is governed by whether one or both the glands is involved. Both the cortex and medulla of each gland exercise important physiological functions. When diseased, they give rise to clear-cut endocrine syndromes, but the clinical picture may become obscured by polyglandular interaction. Adrenal disease, as a consequence, is diagnosed earlier when these effects are present, and usually late when they are absent or obscured.

\section{Endocrine Effects of the Adrenal Glands}

Endocrine manifestations result either from an over- or under-production of the main hormones produced by these organs.

\section{CoRTEX}

(a) The earliest clinical observation associated with disease of the adrenal cortex was made in I 855 by Addison, who described a fatal malady (Addison's disease) characterized by progressive loss of strength, low blood pressure, anaemia and pigmentation of the skin. Subsequent work has shown that adrenalectomized animals can be kept alive by perfusion with cortin (cortical extract) and salt, and later by salt alone. It is now known that two hormones are involved, one concerned mainly with sugar metabolism, the other with mineral metabolism. The application of salt, together with one of these hormones, either eucortone (an extract) or a synthetic preparation (DOKA), form the basis of medical treatment for Addison's disease.

(b) The second main function of the adrenal cortex is concerned with the production of sex characters, in which the cortex plays the part of an accessory sex organ. It has long been known that sex changes were associated with tumours of the cortex. However, it was not until recently that Vines (1933), by means of the ponceaufuchsin stain, was able to show that the responsible matter was present not only in these tumours, but also in most of the cortical hyperplasias.

\section{Medulla}

The third important function is concerned with the adrenal medulla, from which Schafer (1895) succeeded in isolating adrenaline. This substance, apart from its blood pressure raising effects, was later shown by Cannon (1929, 1932) to provide by its liberation into the blood stream, a rapid mobilization of sugar into the tissues for response to immediate action. More recently Dale (1929) has shown that adrenaline and acetylcholine play an important part as chemical buffers between synapses and myoneural junctions in the transmission of nervous impulses along the autonomic system. Clinically, tumours of the medulla are associated with hypertension, especially of the intermittent or paroxysmal type.

\section{Recent Advances in the Physiology of the Adrenal Cortex}

\section{Pathological}

In regarding the adrenal cortex as an accessory sex gland, it is necessary to refer to certain observations emanating from Charing Cross Hospital, which have a bearing on this subject. The ponceau-fuchsin stain is a differential stain which enables us to discriminate between those tumours and hyperplasias of the cortex which are physiologically active and those which are not.

The method has been described elsewhere, and consists briefly of staining a section with fuchsin and counterstaining with methylene blue. The cortical cells in normal controls take up the blue dye, but when sex changes are present, the cells invariably take up the fuchsin dye, and the cytoplasm assumes a vivid red granular colour. The intensity of the colour bears a definite relation to the degree of virility, for a small gland with a marked stain may produce the same clinical signs as a larger gland with a moderate or patchy stain. It therefore appears to exert a qualitative and a quantitative effect.

The wider application of this stain in the sphere of embryology led to the observation that it appears as a transitory phase in the foetus of both sexes. In the male it is marked and lasts between the gth and I 7 th week. In the female it is less marked, and lasts between the IIth and I $4^{\text {th }}$ week. At the end of these times it should normally disappear. It would seem that the postnatal development of virilism in the female may be regarded as the reactivation by physiological stresses of an inherent and unstable 'male phase.' That the termination of this so-called 'male phase' is not absolute was shown in a few full-term foetuses in 
our series when its presence was associated with recognizable sex change such as an enlarged clitoris. The foetal adrenals are comparatively large organs, and shrink remarkably at birth to assume their adult proportions. When they fail to do so, anencephaly results; a phenomenon for which there is no known logical explanation. Should the 'male phase' persist strongly in a female-determined foetus, at the time when the uterovaginal canal is in process of becoming differentiated (up to the I6th week), then there is some reason to expect variations in the structure of the external genitalia. A brief reference to the possibility of partial sex reversal taking place in utero is necessary, for without it the various forms of adult intersexuality would be difficult to explain. Complete sex reversal occurs in the adult stage of certain lower animals such as fowls and fishes, whereas in man it is partial and relegated to the embryonic stage.

\section{BIOCHEMICAL}

The correlation between the fuchsin stain and sex changes clinically led to the assumption that the cortical cells were physiologically active and were concerned with the production of male hormone or its precursor, and that it might be recovered from the urine. The work on this investigation was carried out in the following stages:

\section{Biological or Capon Test}

Urinary assays prepared by Patterson and injected into capons by Greenwood (1938) showed that a comb growth producing substance was present in the urinary extracts of patients with virilism, and that the comb growth was less after adrenalectomy. The test was laborious, timeconsuming, crude but satisfactory. It gave no indication of the nature of the active substance in the assays.

The problem was later solved by Marrion and Butler (1938) of Toronto who, working on the same extracts, succeeded in isolating pregnanetriol, a substance specific to virilism, and likewise diminished in amount by unilateral adrenalectomy. Prognane-triol, however, is a corpus luteum compound, and it was only later, when larger quantities of this substance were available, that they succeeded in breaking it down and found isoandrosterone as one of its chief derivatives.

\section{7-Ketosteroid or Colorimetric Test}

Patterson (1938) elaborated this test, finding it satisfactory from the clinical point of view and giving quick results. The results conformed in general with those of the capon test. The details have been published elsewhere, and it should now be the standard test for virilism. It is a colour test where the final urinary residue is contrasted against a standard colour, and this may account for the wide range of variation we have found in some of the results obtained elsewhere when compared with our own. It is necessary that the test should be reliable and interpreted in relation to the clinical picture.

More recently Patterson (1948) has extended the scope and usefulness of this test by devising a method which differentiates malignant from simple tumours. We have found this test most useful and relied on it even in the big degenerative adenomata where the histology is apt to be doubtful owing to degenerative changes.

\section{Surgical Indications}

Surgery must be considered in the treatment of tumours and hyperplasias.

\section{Tumours of THE Cortex}

These may be simple or malignant, physiological or inert. The latter fall into the group of spaceoccupying tumours, and are usually diagnosed late.

\section{Simple}

Adenomata of the cortex are rare. They produce sex changes with marked rapidity, and their dis appearance is equally dramatic after removal of the tumour. Gordon Holmes (1925) published a typical case of this kind successfully operate upon by Sargent. Wells of Liverpool had an equally successful case (unpublished). His photographs show remarkable changes before and after operation, from the confident and upstanding male to the shy and coy demeanour of the female.

Recently the writer removed an adenoma the size of a walnut from a young lady whose only symptom was hirsuties. It gave on X-ray a small shadow in the right adrenal area. After operation, the ketosteroids fell from $62 \mathrm{mgm}$. a day to 7.9 mgm. a day, and she completely lost her hirsuties.

Two tumours, probably adenomata, though malignancy was suspected, occurred in our series. One, the size of a tangerine in the right adrenal of a child of eighteen months associated with signs of heterosexual precocity, was successfully removed. The other was a huge tumour impacted under the left cupola of the diaphragm in a woman presenting signs of Group 2 virilism with adiposity. The malignancy test was negative, but the tumour was so degenerate that the question of carcinoma remained doubtful. This patient did not survive operation.

Adenomatous nodules are occasionally found in the hyperplastic type of gland.

\section{Malignant}

Carcinomata of the adrenal cortex produce 


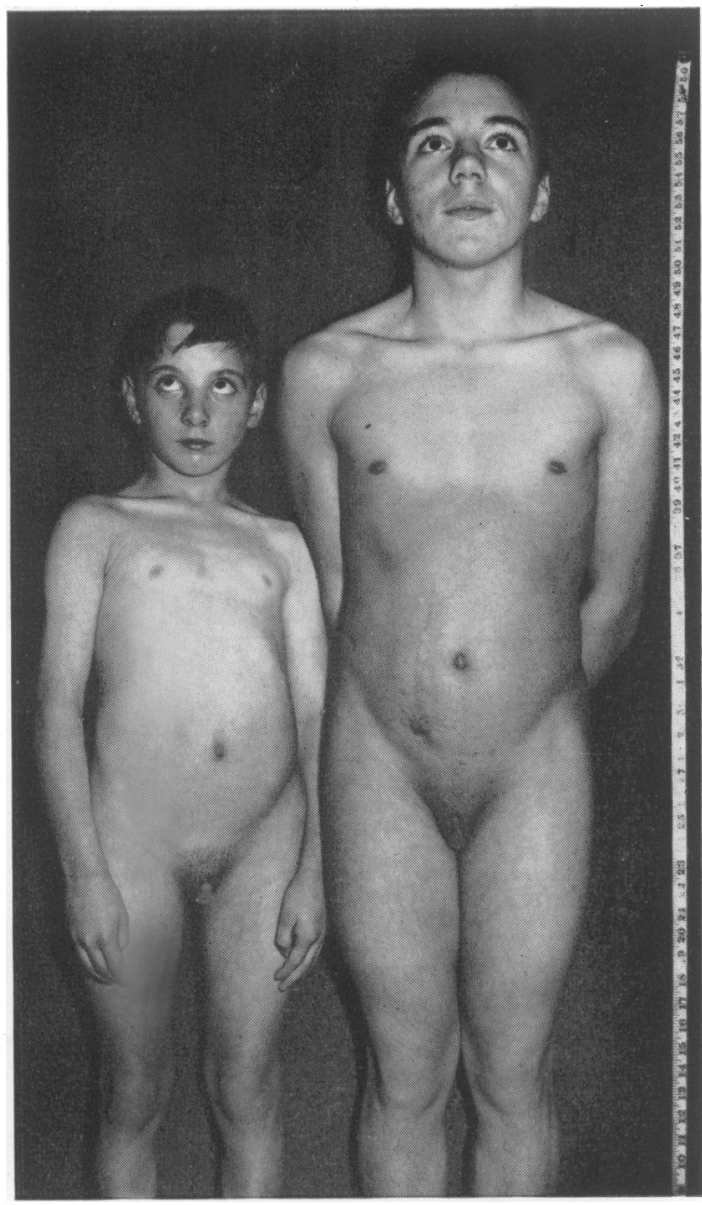

FIg. ra.-Group I virilism. Two sisters aged 6 and 12 brought up as boys. Patient aged 6Pre-operative ketosteroids, $14.7 \mathrm{mgm}$. per diem. Post-operative ketosteroids, $6.7 \mathrm{mgm}$. per diem. Moderately positive ponceaufuchsin reaction. Patient aged I 2-Pre-operative ketosteroids, 56.0 mgm. per diem. Postoperative ketosteroids, $19.0 \mathrm{mgm}$. per diem. Moderately positive ponceau-fuchsin reaction.

different clinical pictures according to the time of onset. In children of both sexes they produce isosexual precocity, and the tumour is likely to arise in a solitary adrenal gland. We have published a case of heterosexual precocity in a girl where the opposite adrenal was present (1948). In the adult it may give rise to Cushing's syndrome. Simpson (1938) published a case of feminism in the male. In elderly women it may produce marked hirsuties. In one patient a $5 \frac{1}{2} \mathrm{lb}$. carcinoma was removed from the right side. The ketosteroids dropped from $404 \mathrm{mg}$. a day to 4.8 mgm. a day, and she completely lost her beard. Fifteen months later, with the appearance of

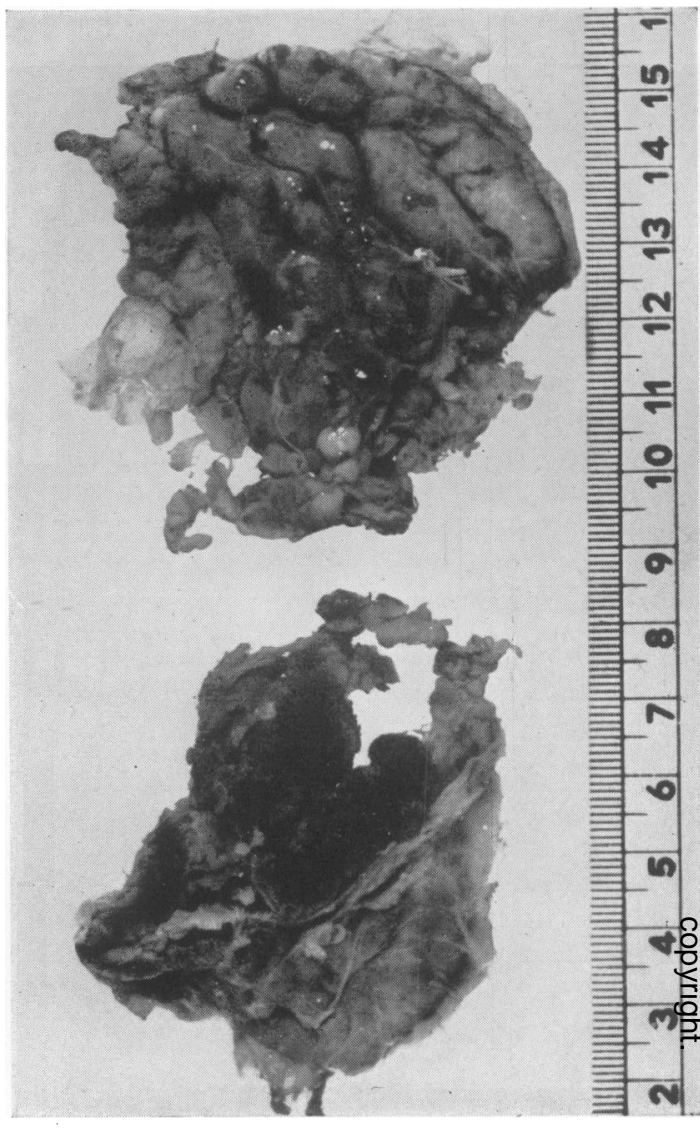

FIG. Ib.-Adrenals removed from these two patients.

secondary deposits, the beard had reappeared and the ketosteroids had risen to $94 \mathrm{mgm}$. a day (1950).

Differential Diagnosis. . In children, the differen-을 tial diagnosis becomes important in the study of isosexual precocity (Walton, 1950). In this con- 3 . dition there is a premature development of the primary and secondary sex characters, which may assume the adult proportions appropriate to their 0 own sex. These children are not only an embarrassment to their parents, but are apt to become $\frac{D}{2}$ a social nuisance.

A raised ketosteroid output suggests a diagnosis $N$ of adrenal carcinoma. In the present series theren have been four cases (two boys and two girls) of carcinoma in a solitary adrenal gland, and the $e_{\sigma}^{\omega}$ writer knows of three other cases elsewhere. The condition is therefore not too uncommon to merite careful investigation before the tumour is uselessly removed. Preliminary laparotomy is essential.

A similar clinical picture may arise with $\frac{0}{\mathrm{P}}$ hypothalamic tumour. The symptoms in such ad 


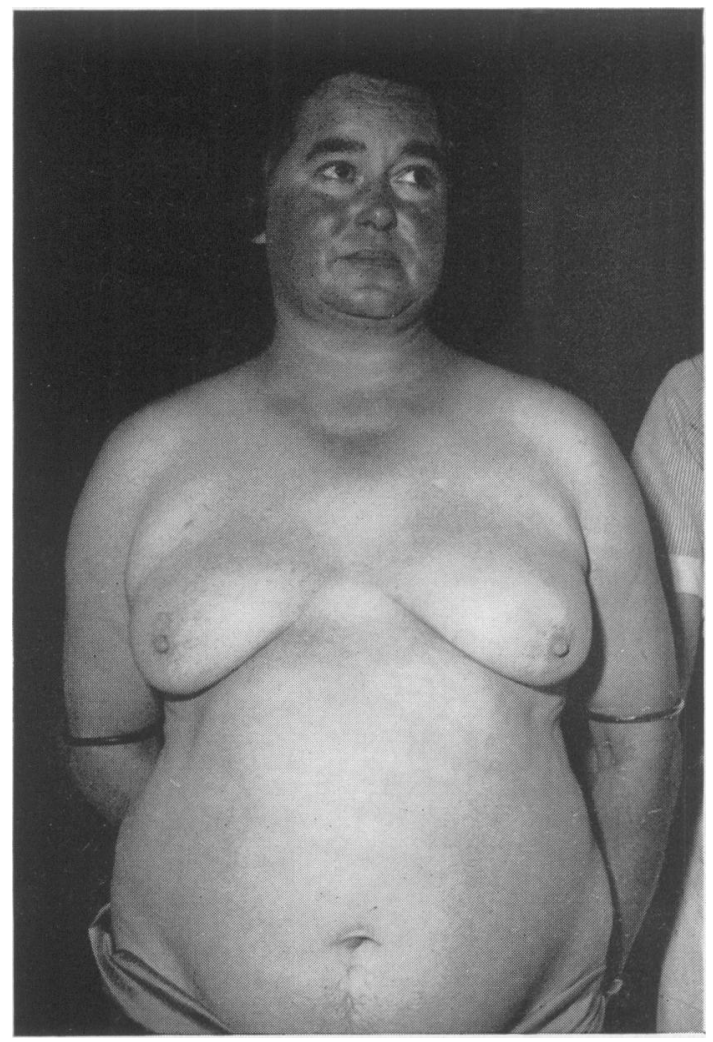

Fig. 2a.-Case of Cushing's Syndrome.

case seem to depend not on the nature of the tumour but rather on pressure effects in the juxtapituitary region. Dott and Le Marquand (unpublished) drew attention to this condition before the introduction of the ketosteroid test. Neurologically these tumours are difficult to diagnose.

Granulosa celled tumours of the ovary advance the development of the sex characters, and can be diagnosed by the excess oestrin which they secrete. Menstruation is said to be anovular.

The 'Pocket Venus' Type, where no pathological cause can be found. These girls appear normally but prematurely advanced in their development, and form the group of mothers who beget children before the age of puberty.

\section{Tumours of the Medulla}

The cells of the medulla consist originally of primitive neuroblasts, and give rise to tumours either of the sympathetic neurone or of the chromaffin cells. Three types of tumour occur,

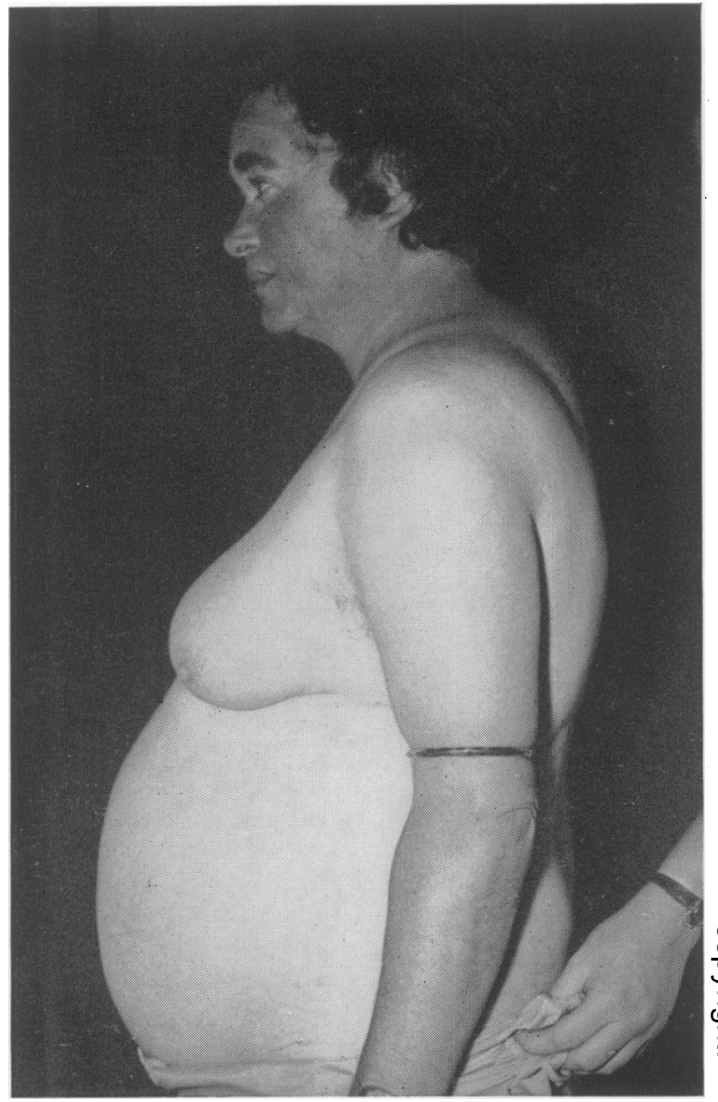

Fig. 2b.-Age 43. Pre-operative ketosteroids, 35.0 mgm. per diem. Post-operative ketosteroids, $21.5 \mathrm{mgm}$. per diem. Ponceau-fuchsin stain showed no definite positive reaction.

two of which are physiologically inactive and one is strongly active.

\section{Physiologically-inactive Tumours}

Ganglioneuromata are rare and generally benign. They may occur in children or in adults, and have a tendency to become multiple.

Neuroblastomata occur in children. They are highly malignant and give rise to extensive metastases in a definite pattern, according to the gland involved. On the right side (Pepper's syndrome) metastases occur in the liver, which may reach enormous dimensions. On the left side (Hutchinson's syndrome) the secondaries are chiefly in bone, particularly of the skull, and there is characteristically a unilateral proptosis of the left eye.

\section{Physiologically-active Tumours}

Phaeochromocytamata or paragangliomata are tumours of the chromaffin cells of the adrenal 
medulla. They secrete adrenaline and produce marked hypertension which is usually paroxysmal, sometimes constant. During an attack, the patient feels faint, anxious, apprehensive, and may collapse. The face may become pale and moist, and the extremities cold and blue. These vasoconstrictive attacks vary in intensity and may be associated with nausea, giddiness, headache, palpitations and weakness in the legs. During the attack, which may be transient or may last for several days, the blood pressure is raised, and unless this is noted, these rather vague or subjective symptoms may be ascribed to neurosis.

Illustrative Cases. A young airman began to suffer from vasoconstrictive attacks when flying. A similar attack followed cystoscopy. On examination he had complete transposition of viscera with mild signs of feminism. A phaeochromocytoma containing excess of adrenaline and weighing $63.5 \mathrm{gm}$. was removed. Within ten minutes his blood pressure fell from 225/145 to $90 / 70$, and had to be restored by intravenous adrenalin. He made a complete recovery (I944).

A second patient, a woman, died during a paroxysm during investigation. An intravenous pyelogram showed a depressed upper calyx of the right kidney and autopsy confirmed this as the site of the tumour.

A third patient, also a woman, complained of hypertensive attacks. During laparotomy the right adrenal was thought to be slightly thickened. On squeezing it firmly, the blood pressure was raised. At a later date the right adrenal was removed, and showed a small cystic tumour in the medulla.

These tumours are generally benign, and tend to occur before the age of forty. If removed before the vascular system has become too strained, the prognosis is excellent.

Medullary tumours may produce a weak fuchsin reaction in the cortical cells and mild changes in the secondary sex characters. This clinical observation, when present, may prove helpful in arriving at what is a difficult diagnosis.

\section{AdRENO-CoRTICAL HyPERPlasias-Adreno- GeNital SyNDROME}

The commonest form of cortical hyperfunction is to be found in the hyperplasias, with varying degrees of virilism.

Virilism may be defined as the appearance of male secondary sex characters in the female. The earlier its signs appear the more marked they become. When they appear later they may be complicated by secondary symptoms suggestive of polyglandular disturbances (I946).
Virilism may be classified into four main groups:

Group I. Prepuberal virilism.

Group 2. Postpuberal virilism.

Group 3. The Cushing or fat type.

Group 4. Post-menopausal virilism.

This condition in general terms is distinguished by the appearance of male secondary sex characters in the female, and the more marked this feature is the greater the suppression of the feminine sex characters and function. Depending upon the age of onset and the degree of hyerplasia of the adrenal glands, there is a wide range of variation in the clinical manifestations. These may be summarized as follows:

\section{Male Changes}

(I) There is a shift towards the male figure involving skeletal structure, muscular development and disposition of body fat.

(2) The clitoris is enlarged.

(3) The voice deepens and the larynx is enlarged.

(4) Skin changes, involving growth of hair of the male type and distribution, occasionally baldness and coarsening of the texture of the skin with acne.

\section{Female Changes}

(I) The breasts either do not grow, remain small or may retrogrcss after full development.

(2) The labia and vagina are poorly developed.

(3) The uterus may be small and infantile.

(4) The ovaries may remain immature, or later become cystic and degenerate.

(5) The menses may never appear; if they do they become irregular, scanty or cease altogether.

(6) Fertility is decreased.

Associated with these somatic changes certain psychological symptoms may appear. These patients tend to react morbidly to their condition, they are depressed, frustrated and feel inferior beings socially. In some there are definite changes in sexuality and personality and in a few frank psychosis.

\section{Group I. Prepuberal Virilism (2 I cases)}

Prepuberal virilism becomes manifest at or before puberty when the secondary female sex characters and the sex function fail to appear in girls. Occasionally it may be established at birth, when a large clitoris is present, and this is followed. by the precocious development of pubic and axillary hair. These children are of the tom-boy. type (Figs. Ia and b) ; they have short limbs with a muscular body and show a preference for active games. The voice may be rough and deep. If they reach puberty without these signs, then obvious. changes occur in two directions, the failure of 


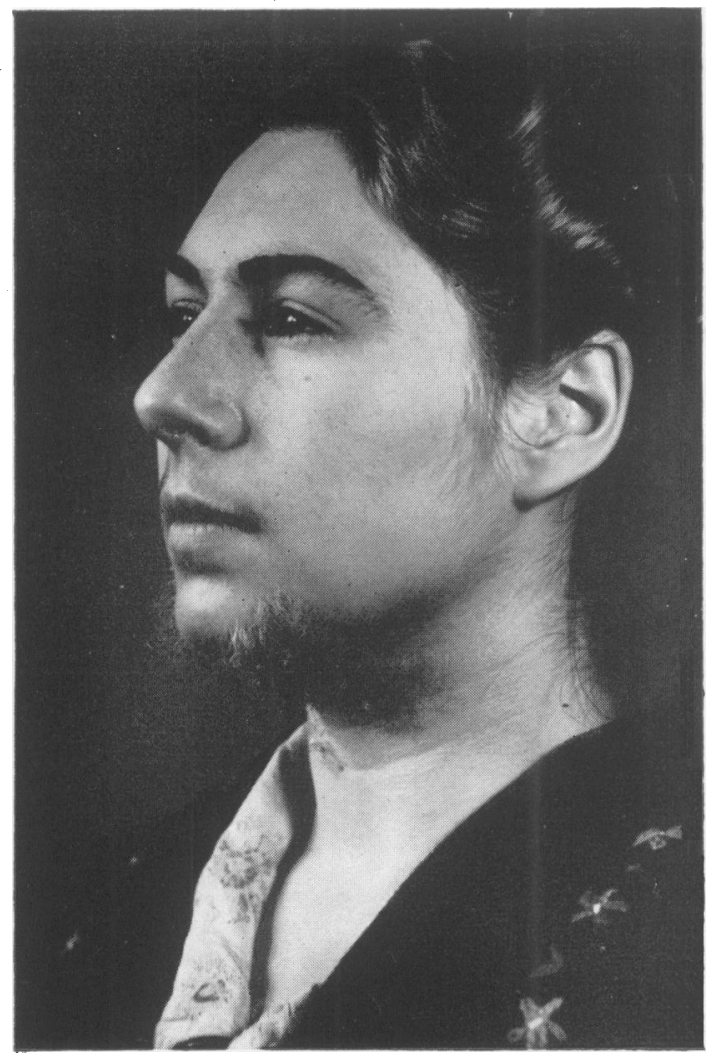

FIC. 3.-Group II virilism in a woman aged 21 . Chief symptoms, hirsuties, sterility and diminishing menstruation. Ketosteroids before operation, $67 \mathrm{mgm}$; after operation 14.4 mgm. per diem.

feminine development and the appearance of secondary male sex characters.

The figures of these girls are boyish, the shoulders are broad and the pelvis narrow, the lower jaw and supra-orbital ridges are accentuated, and the general muscular development stands out in contrast to the normal, soft, rounded contours of the female. On the female side the menses do not start, the breasts fail to grow, the external genitalia remain puelline, the uterus and cervix are infantile, and the ovarian follicles do not ripen. Hair of the curly crisp type begins to grow on the face, limbs and trunk, and shaving becomes necessary. The voice cracks and becomes deep and rough. The clitoris is enlarged and the labia and vaginal orifice are small and narrow. It is not surprising that such gross changes should have a marked effect upon the personality of the patient. They tend to withdraw within themselves and to shun society. At this early age it is not easy to assess their sexuality and, in spite of their female conditioning, it may be neuter, indifferent or homosexual; indeed, one patient, after behaving as a male, was subsequently married twice as ? female. The condition progresses slowly, the patients looking older than their age, and they may start to become bald at the age of twenty.

The writer has operated on 21 cases in this group, varying in age from five to thirty-one, with an average age of sixteen; 4 at the ages of one, five, six and seven with signs of precocity, and 17 after the age of puberty. They all had male figures, hirsuties, deep voices, enlarged clitorides, either small or no breasts and primary amenorrhoea.

Pathology. There is marked bilateral hyperplasia of both adrenal glands varying from 10 to $48 \mathrm{gm}$. each. They may reach the size of a normal spleen. As they grow they become more and more pigmented. The ponceau-fuchsin stain is strongly positive. The uterus, cervix and tubes are infantile, and the ovaries are small and smooth. There may be some small cysts, but they do not ripen and no corpus luteum is present.

Biochemistry. The results of estimations of 17 -ketosteroid output in mgm. per day are as follows:

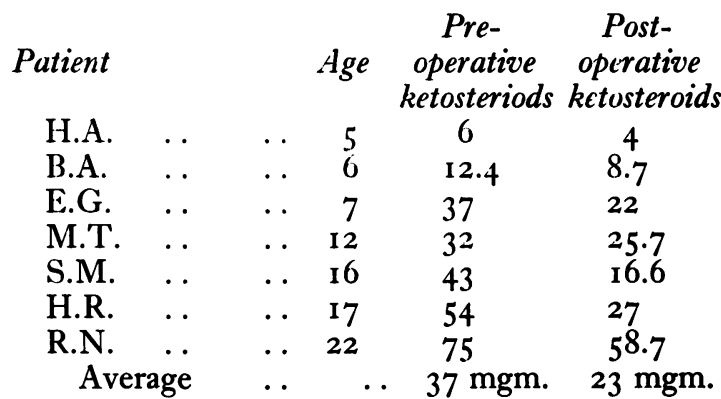

It will be seen from these results that the 17ketosteroid excretion rises with increasing age. The third patient gives a good idea of the inexorable progress of this condition. She had an unusually high 17 -ketosteroid output of $37 \mathrm{mgm}$. at the age of seven when the left and larger of the two adrenal glands was removed. During puberty the clinical condition became worse and she became an embarrassing social problem to her family. She also had an elder brother with isosexual precocity. At the age of fourteen, her I7ketosteroid output having advanced to $100 \mathrm{mgm}$. a day, a rise of $63 \mathrm{mgm}$. in seven years, $19 \mathrm{gm}$. of her remaining adrenal gland were removed, with fatal result. Three patients who had beer operated on before these biochemical tests were available showed an average 17-ketosteroid excretion of $60 \mathrm{mgm}$. between two and five years after operation. In 2 I cases there have also been two fatalities in this group after subtotal adrenalectomy, and three from unilateral adrenalectomy (Jones, 1949). 
All passed into a state resembling acute hyperthyroidism, with a falling blood pressure and rising pulse rate. We have found Lugol's solution helpful in these advanced cases after operation, but they constitute a major surgical problem.

From our experience so far it would seem that the limits of surgery begin to be reached when each gland weighs over $25 \mathrm{gm}$. and where the $17^{-}$ ketosteroid output exceeds $100 \mathrm{mgm}$. a day. The other patients have done well and lead active and useful lives and, although the post-operative ketosteroid output appears to rise with age, their clinical condition has not deteriorated. The question is whether these results warrant adrenalectomy. The steady progress of the condition without operation would appear to give the answer. Surely the patient is entitled to whatever amelioration there is, even at considerable risk, in an otherwise desperate and hopeless condition. It is reasonable furthermore to argue that earlier operation may offer a better chance in preventing clinical deterioration which is often accentuated during puberty. The results in this group are thus assessed as in statu quo.

Differential Diagnosis. There are three types of case which are clinically indistinguishable from Group I virilism. They are the true hermaphrodite, the intersex and the cryptorchid. It is only by laparotomy and biopsy of the sex gland that a definite diagnosis can be made. The androgen output may be raised in these cases, but not nearly so high as in Group I virilism.

\section{Group 2. Postpuberal Virilism (12 I cases)}

It is to this group that the majority of our patients belong. Many are instances of familial hirsuties, their symptoms are mild and they do not require operation. It is common among Jews and in the offspring of parents of mixed nationalities. In some the condition seems to arise from endocrine imbalance during pregnancy, especially twin pregnancies. Other endocrine lesions are fairly often traced in the family histories.

Clinical Condition. In this group the patient, having passed normally through puberty, at the age of fifteen to twenty-five begins to grow hair of the male type (Fig. 3) whilst the periods become irregular or cease. In some there is a temporary increase in weight and severe headaches of the migrainous type may occur. The same symptoms, with regard to the retardation of feminine characters and functions and the accentuation of male characters, occur as in Group I, but to a lesser degree. The severity of one or other of the more undesirable symptoms, or their combination, must be the clinical guide with regard to the performance of unilateral adrenalectomy.

Although the majority of these women are normally heterosexual, it is in this group that the most marked psychological changes have been observed. They occur in varying degree. Changes in sexuality range from frigidity to narcissism or frank homosexuality. In a few there has been paranoid psychosis, in which anorexia of the nervosa type, delusions and persecution play a part, leading to suicidal tendencies. The details of these conditions are a specialized study and have been published elsewhere by Clifford Allen (1939). The psychological reaction may be temporarily aggravated by unilateral adrenalectomy, but, on the whole, these unpleasant symptoms have been improved by operation and, in this respect, the psyche and soma have run on parallel lines.

Pathology. There is a bilateral hyperplasia of the adrenal glands, varying from 2.3 to $8.8 \mathrm{gm}$. The fuchsin stain is invariably present in the cortical cells, and its intensity bears a direct relation to the degree of virilism present. The results are better in those cases where the larger of the two glands is removed.

Biochemistry. The excretion of androgens is raised, and the output, taken in conjunction with the clinical picture, forms a useful guide in coming to a decision with regard to the question of operation. The average decrease in output aftes operation is 50 per cent., and the larger the decrease the better the result.

The biochemical results in $4 \mathrm{I}$ cases expressed as mgm. I7-ketosteroids excreted per day are shown in the table:

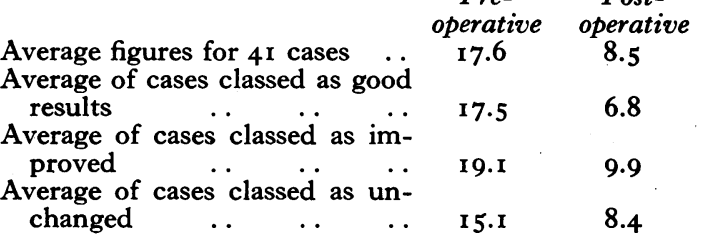

The average drop is about 50 per cent. and, where this fall is larger, leaving the post-operative figure low, the results are better.

Results of Treatment. The prognosis in these cases is good. In 121 unilateral adrenalectomies in this group there has been no mortality. The hair can be plucked out fairly easily without much pain 48 hours after operation, the complexion and any acne of the skin is improved, and menstruation becomes more regular and fertility and sexuality are increased. The degree of improvement varies and can be subsequently helped by hormonal therapy if necessary. The majority of the patients are satisfied that something has been done for an unpleasant and embarrassing condition, which gives a guarantee against its further 
progress. Medical treatment is limited in scope and, until some potent anti-androgenic factor is discovered, operation is the treatment of choice.

The clinical results may be tabulated as follows:

\begin{tabular}{|c|c|c|c|c|c|c|}
\hline Average & age & twenty- & & & ved over & 16 years \\
\hline & & & Mor & $\begin{array}{c}\text { ality nil. } \\
\text { Group } 2 \\
\text { cases }\end{array}$ & $\begin{array}{l}\text { Cushing's } \\
\text { syndrome }\end{array}$ & $\begin{array}{c}\text { Psycho- } \\
\text { logical }\end{array}$ \\
\hline Totals & - & $\cdots$ & $\cdots$ & 88 & 14 & I 5 \\
\hline Good & & $\ldots$ & . & I6 & 2 & 5 \\
\hline Improved & & . & . & 45 & I I & 8 \\
\hline i.s.q. & & $\cdots$ & .. & I0 & I & 2 \\
\hline Def & & mation & .. & I4 & - & - \\
\hline Died fr & mo & er cau & es. . & 3 & - & - \\
\hline
\end{tabular}

\section{Group 3. The Cushing or Fat Type}

Cases in this group are common. They are hefty, hairy women, the onset of whose symptoms is similar to Group 2, with the difference that they run to fat. They comprise varying grades between the extremes of Group 2 and Cushing's syndrome, with or without one or more of the secondary symptoms of the latter. Usually menstrual disorders are more marked than hirsuties. In those patients who have a high output of androgens, adrenalectomy should be carried out, and a positive fuchsin stain is generally present in the gland.

Treatment is primarily medical and consists of a low calorie diet with fixed fluid intake, iodine and oestrogens.

\section{Group 4. Post-Menopausal Virilism}

This group comprises those bearded women after the menopause, so often seen in asylums. Adrenalectomy is contraindicated.

\section{Cushing's Syndrome}

Cushing's syndrome may be defined as secondary virilism on which a pathological oberity and other secondary metabolic symptoms have been superadded.

Clinically, the onset of hirsuties and menstrual irregularities in the female is as in Group 2. At this time they begin to develop a gross adiposity, accompanied by a ruddy complexion (Figs. 2a and $b$ ). This red colour is also distributed over the breasts and extremities, and, in the form of vivid red ' striae distensae,' radiates round the pubes, on the abdomen, flanks and groins. Hair is not so marked and is more of the downy type. Amenorrhoea is common. These patients have a low basal metabolic rate like myxoedema, but when interfered with surgically, they become anxious and develop a rapid pulse rate resembling hyperthyroidism.

The secondary symptoms are revealed by special investigations. There is erythrocythaemia with a raised colour index, together with excess of cholesterol in the blood and a low sugar tolerance verging on glycosuria. X-ray of the pituitary fossa generally shows a small sella. The blood pressure is raised.

Differential Diagnosis. It is impossible to make a differential diagnosis clinically as to whether the condition is caused by a basophil adenoma of the pituitary, or hyperplasia or neoplasm of the adrenal cortex, except by the ketosteroid test. If the ketosteroid test is within normal limits, a diagnosis of pituitary basophilism can be made. If it is moderately raised it is due to adrenal hyperplasia, and if excessive, it is due to adreno-cortical carcinoma. On our standard, the normal limits range from 7 to $14 \mathrm{mgm}$. per day. An excretion of $30 \mathrm{mgm}$. or more would indicate hyperplasia. One case of adrenal carcinoma excreted $270 \mathrm{mgm}$. per day.

\section{Treatment}

\section{Adrenal Hyperplasia}

When the ketosteroid test reveals a high output, laparotomy followed by removal of the larger adrenal should be performed.

\section{Pituitary Basophilism}

In our experience $\mathrm{X}$-ray treatment to the pituitary fossa has not been helpful. We have recently adopted a form of treatment which has proved successful. It is purely empirical and theoretically aims at influencing the pituitary via the thyroid and ovary. A case of thi: kind may be cited:

The patient, a girl twin of sixteen, under Dr. Gordon Holmes, was referred to us, with marked Cushing's syndrome. She was short, florid and very fat. Her ketosteroid test done elsewhere was $22 \mathrm{mgm}$. per day; our result was $14 \mathrm{mgm}$. per day. She had primary amenorrhoea, her bones were rarified with some collapse of two lumbar vertebrae, and she was nursed in a spinal jacket. She developed bronchitis, marked oedema, and a rapid pulse, and appeared moribund. She was given Embleton's diet, with a $50 \mathrm{oz}$. fluid intake, Lugol's iodine (10 min., t.d.s.) and an oestradiol implant into the groin. She slowly improved, started to menstruate and some months later had lost most of her weight and could walk eight miles a day.

This treatment, with a testosterone implant, was tried in a similar case on a soldier. He did not respond to the same extent and, as his ketosteroid output remained in the region of 30 to $50 \mathrm{mgm}$. per day, unilateral adrenalectomy was performed. When he left hospital he had lost $2 \frac{1}{2}$ stone in weight.

\section{Assessment of Results}

The clinical results assessed in the table above 
are of the writer's own cases and are based on the psychosomatic reactions of the patient to the operation, and on an evaluation of the alleviation of individual symptoms. Observations from two independent sources confirm the writer's evaluation; the first from Dr. Geoffrey Andrew who carried out a postal follow-up, and the second from Dr. Leonard Simpson (1946).

\section{The report by Dr. Andrew:}

'Migrainous headache and depression. One or both of these symptoms were present in nearly every case. The headache was abolished in most cases; even where the operation had failed to reduce hypertrichosis or obesity it succeeded here. Many of the patients were thoroughly grateful for this relief. Some cases were still depressed at times after operation; this was usually because the hypertrichosis had not diminished as much as expected.

'Hypertrichosis. Moustaches, beards or side whiskers were usually the main feature that drove the patients to seek advice in the first place. In must cases it produced noticeable psychological reactions, unless these are to be considered as primary to the syndrome, i.e. part of the syndrome and not a result of it. Most of the patients were prepared to go to much trouble to get rid of the excessive hair.

'In this respect, operation in some cases only produced fair results. Only once or twice was the hairiness abolished completely enough to allow the patient to call herself normal. In many cases the adrenalectomy reduced the hirsuties sufficiently to allow of easy removal of the hair with tweezers. A few patients noticed the hair diminished both in abundance and coarseness, and they were grateful for this. The majority of patients were satisfied with the degree of improvement. The remainder were frankly dissatisfied. This was either because they had observed no improvement, or because they had been led to expect excellent improvement by injudicious reports in the public press about it.

'It might be added that it is as difficult to persuade a woman to shave or remove her hair after operation as it is to dissuade her from operation when this is the main symptom, as it not infrequently is.

' Obesity. As obesity was not a feature in all cases, these remarks apply to those where it was present and was a source of worry. In some the operation produced excellent results. In others it was disappointing.

'Menstruation. Many of the patients complained of irregular periods. Some had severe pre-menstrual dysmenorrhoea. Most of the patients obtained some relief in this respect, either relief from dysmenorrhoea or the occurrence of more regular periods. Some had little or no relief. There was a tendency among the patients to use the improvement in the periods as a yardstick of success of the operation. Those cases where conception subsequently occurred were very grateful and this was one of the really encouraging features of the operation, as sterility was a not uncommon complaint.

' General health. This improved in nearly all cases. Even some of those cases labelled "neurotic" confessed that they had been in better general health than hitherto.

' Conclusions. In well-selected cases the operation is undoubtedly successful in amelioration of the symptoms. In others it failed. These were cases who pressed for the operation in spite of warning, and the correspondence made this clear.

' I consider this to be a fair statement of the effects of operation on individual symptoms. Where it succeeds in some it may fail in others. There are obviously complex factors concerned in such a wide range of symptomatology, in which the adrenal plays an important but variable part in a polyglandular syndrome. It is obvious that the present state of our knowledge does not enable us to predict with precision the amount of benefit which will take place in any given individual.'

\section{Dr. S. Leonard Simpson's case:}

A woman aged twenty-six years had married at the age of seventeen, and had had two miscarriages. She contracted gonorrhoea from her husband, and was operated upon for pelvic peritonitis. She was subsequently divorced, and lost all interest in her sexuality.

For the past I4 months she had experienced menstrual irregularity with diminishing flow from from 4 days to $I$ day with bouts of amenorrhoea. During this time abnormal hair began to grow on her face, legs and abdomen. She was worried, depressed and self-conscious about her condition and began to shun society.

In June 1944 her left adrenal was removed. It weighed $8 \mathrm{gm}$. There were two subcortical adenomata. Vines's ponceau-fuchsin stain gave a moderately intense positive result in the zona fasciculata where the hypertrophy was most marked. The 17 -ketosteroid excretion rose from 12.6 in 1943 to 17 and $19.3 \mathrm{mgm}$. in 1944 . After operation it dropped to $13.5 \mathrm{mgm}$. Dr. Simpson wrote in August 1946:

'There is positive evidence, both subjective and objective, of improvement amounting to clinical cure. Since the operation the hair has completely fallen off the sides of the face and persists on the chin and upper lip in a very much finer 
texture than before the operation. This is also true of her legs, on which, when she shaves them, no black spots are left as there were before operation. She plucks the hair from her face and bleaches her hair, but is successful in her efforts, whereas before operation she could not control its growth. All the hair round the nipples has disappeared; also the upgrowth of hair from the pubis to the umbilicus. In addition I noticed that the pubic and axillary hair was, if anything, somewhat scanty. The rather unusual feature is her report of loss of hair on the vertex of the head immediately after adrenalectomy. It then grew again, but fell out after influenza last winter. It grew again after this, but has now receded from the temples and is coming out in some degree generally. This is somewhat anomalous, as loss of hair of the head is usually associated with growth of hair on the face and body. The texture of the hair of the head is much finer. She also reports that her breasts have grown to normal size again and that she has put on a little fat around the hips. She has not, however, gained appreciably in weight. A cousin remarked at the onset of the trouble that she became as flat as a board and lost her womanly shape, which she has now regained. As to menstruation, she had almost complete amenorrhoea before the adrenalectomy, but after this there was a slight show (three days later) and ever since she has menstruated regularly at intervals of 26 days. Although restless and somewhat unstable, her general outlook has changed from deep depression and desperation to one of happiness and cheerful expectancy, amounting almost to euphoria. She is friendly with a man whom she anticipates may become her husband.'

\section{Psychological Results}

There is now sufficient evidence to show that definite improvement in psychological outlook can occur after operation in those patients where it was abnormal. In 15 cases, there has been improvement in 13 , with failure in 2 . One of the latter wàs a German refugee, who had lost her relatives and spoke no English. She was operated upon during the war at a time when we were unable to obtain expert psychological help and guidance. The other lived at a distance and quarrelled with an elderly husband with stepchildren.

As this syndrome carries with it characters which are not normally feminine it is not surprising that these women resent what is fundamentally an unjust biological and social imposition. They become emotionally upset, shy, secretive, selfconscious, frigid and depressed to the point of desperation. Later they may become difficult to manage, wayward, capricious, uncooperative, slovenly in their appearance and habits, and may develop delusions of persecution and ostracism. It is not surprising that any amelioration of their physicial and functional disabilities should be followed by an improvement in their general outlook. More obscure is their increased sexuality, the feeling of euphoria and sooner or later the loss of their delusional states which follows operation. The biochemical results in this group are too small to form any definite opinion, but the most successful have shown a comparatively low pre- and post-operative ketosteroid output with a post-operative fall of over 50 per cent.

Two of the most advanced cases in this series have been published by Clifford Allen (1939) and have remained well for two and eight years respectively.

\section{Pre-Operative Investigations}

The ketosteroid test gives the best indication of the degree of adreno-cortical activity.

In Cushing's syndrome, the blood pressure, blood count, blood sugar and blood cholesterol should be determined.

\section{For HyPERPLASIA}

Laparotomy is a safe and useful guide for deter-을 mining which adrenal to remove. A paramedian incision is made to the right of the umbilicus long? enough to admit the hand. The pelvic organs are palpated to detect any abnormality, and to exclude arrhenoblastoma of the ovary or aberrant adrenals. Each adrenal is then palpated to see which is the larger. In the majority of cases this can be satisfactorily determined. The adrenal is generally larger on the same side as the more degenerate ovary. Laparotomy is a safe procedure and would seem preferable to the simultaneous exposure and removal of a portion of each adrenal gland. Adrenalectomy can be performed a fortnight later.

\section{For TUMOUR}

(a) An intravenous and, if necessary, a retrograde pyelogram should be performed. Distortion of the upper calyx and depression of the kidney gives the earliest hint of the presence of a tumour.

(b) X-rays after perirenal insufflation with air or oxygen by means of a needle attached to a manometer has not proved of great value. Laparotomy is as safe and gives more precise and general information.

\section{Operative Technique}

Unilateral adrenalectomy may be performed through the chest or through a high kidney 
incision. Special instruments and retractors made by Meyer and Phelps are helpful.

\section{Thoracic Approach}

An incision is made along the intercostal space between the Ioth and IIth ribs. The thoracic cavity is opened, the ribs are retracted, and the diaphragm incised. The adrenal is held in special forceps and dissected from its bed. The diaphragm is repaired and the wound closed.

\section{The High Kidney Incision}

An incision 6 to $8 \mathrm{in}$. long is made parallel to the last rib, and the muscles are divided. If the last rib is small it is resected sub-periostally and entrance gained into the perinephric fat by incision through its bed. If it is a large rib, two holes are made an inch apart at the neck, and the rib divided between them. A strong ligature is threaded through the holes and left in situ to be tied when closing the wound. The perinephric fat is opened, the kidney held down with a special retractor, and a deep retractor pulls up the ribs. The adrenal gland is defined and caught in spesial forceps. Positive pressure is now applied by the anaesthetist and the gland dissected from its bed. The main vein seen on its inner border is then tied and the gland freed and removed. The vein is weak and if accidentally torn may give rise to alarming haemorrhage. This is more likely to happen if the diaphragm or vena cava are allowed to flap. The rib is then tied and the muscle layers are repaired with interrupted catgut. No drain is nesessary and the skin is closed. Depending on the width of the subcostal angle, the plural or peritoneal cavity or both may be accidentally opened.

This operation has a shorter convalescence than the thoracic one, for in the latter, the lung may take some time to expand.

\section{BIBLIOGRAPHY}

ALLEN, C., et al. (1939), Brit. med. F., i, 1220.

BROSTER, L. R., and VINES, H. W. C. (I933), 'The Adrenal Cortex, London, H. K. Lewis.

BROSTER, L. R., ALLEN, C., VINES, H. W. C., PATTERSON,

J., GREENẄOOD, A., MARRIAN, C. F., and BUTLER, G. C. (1938), 'The Adrenal Cortex and Intersexuality,' London, Chapman and Hall.

BROSTER, L. R., and MCKEITH, R. C. (1943-44), Brit. F. Surg., $31,303$.

BROSTER, L. R. (1947, 'Adrenal Glands,' Brit. surg. Pract., 1. BROSTER, L. R. (1946), Proc. roy. Soc. Med., 40, 35.

BROSTER, L. R., and PATTERSON, J. (1948), Brit. med. $f$. i, $78 \mathrm{I}$.

BROSTER, L. R. (1950), Brit. Med. F., i, I17I.
CANNON, W, B. (I920) 'Bodily Changes in Pain, Hunger, Fear and Rage,' Second edition, New York and London, Appleton and Co.

CANNON, W. B. (1932), 'The Wisdom of the Body,' London Kegan Paul.

DALE, SIR H. (1929), Lancet, i, 15.

DALE, SIR H. (1933), 'Progress in Autopharmacology,' 53.

DALE, SIR H. (1937), F. Mt. Sinai Hosp., 4, 401.

HOLMES, G. (1925), Quart. 7. Med., 18, 143.

JONES, B. V. (1949), Brit. med. F., ii, 1023 .

SCHAFER (1895), Four. Soc. Phys., r8, 230.

SIMPSON, S. L., and JOLL, C. A. (1938), Endocrinology, 22, 595

SIMPSON, S. L.' (1946), Proc. Roy. Soc. Med., 40, 2, 35.

WALTON, A. (1950), Charing Cross Hosp. Gaz.. 48, 3 .

BIBLIOGRAPHY for 'Physiology of Growth'-(c mtinued.from page 424)

EVANS, H. M., SIMPSON, M. E., and LI, C. H. (1943), Endocrinology, 33, 237.

NEL-COURAT, H. L., MEAMBER, D. L., SIMPSON, M. E., and EVANS, H. E. (1940), Endocrinology, 27, 605 .

FREUD, J., and LEVIE, L. H. (1938), Arsh. Intern. Pharmacody'n, FREƯD, J.,

. H., and KROON, D. B. (1939), F. Endocr.,

GAARENSTROOM, J. H., and LEVIE, L. H. (1939), f. Endocr.,

GAARENSTROOM, J. H., HUBLE, J., and DE JONGH, S. E. (1949), F. Endocr., 6, 71 .

GARDNER, W. U., and PFEIFFER, C. A. (1943), Physiol. Rev., $23,139$.

(1950), Brit. Med. F., 1, 1165

KINSELL, L. W., MICHAELS, G. D., LI, C. H., and LARSEN, W. E. (1948), F. Clin. Endocr., 8, 1013.

LEE, M. O., and SCHAFFER, N. K. (1934), Ұ. Nutrit., 7, 337

LI, C. H., and EVANS, H. M. (1944), Science, 99, 183 .

LI, C. H., EVANS, H. M., and SIMPSON, M. E. (1945), f. Biol.

Chem., 159, 353 .

, C. H., SIMPSON, M. E., and EVANS, H. M. (1949), Endocrinology, 64, 71.
LI, C. H., GISCHWIND, I., and EVANS, H. M. (1949), Endocrinology, 44, 67.

LI, C. H. (1950). Lancet 1, 213 . V., and EVANS, H. M. (1044),

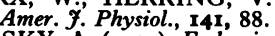

MIRSKY, A. (1939), Endocrinology, 25, 52.

MOON, H. D. (1937), Pro?. Soc. Exp. Biol. Med., 37, 34

REIFENSTEIN, E. C., KINSELL, L. W., and ALBRIGHT, F. (1946), f. Clin. Invest., 25, 932.

REISS, M., FERNANDES, J. E., and GOLLA, Y. M. L. (1946),

Endocrinology, 38, 65.
RIDDLE, O., and BATES, R. W. (1938), f. Biol. Chem., 123, 5. SALMON, T. N. (1941), Endorrinology, 29, 291 .

SILBERBÉRG, M., and SILBERBERG', R. (1941), Amer. F. Anat., 69, 295 .

SIMPSON, M. E., KIBRECK, E. A., BECKS, H., and EVANS, H. M. (1942), Endocrinology, 30, 286.

SIMPSON, M. E., MARX, W., BECKS, H., and EVANS, H. M. (1944), Endocrinology, 35, 324.

SMITH, P. E. (I930), Amer. Y. Anat., 95, 205.

SMITH, P. E., and MCDOWELL, E. C.'(1930), Anat. Rec., 46, 249.

SPRAGUE, et al. (1950), Arch. Intern. Med., 85, 199.

YOUNG, F. G. (1944), Brit. Med. Y., ii, 715.

YOUNG, F. G. (I945), Biochem. F., 39, 515. 